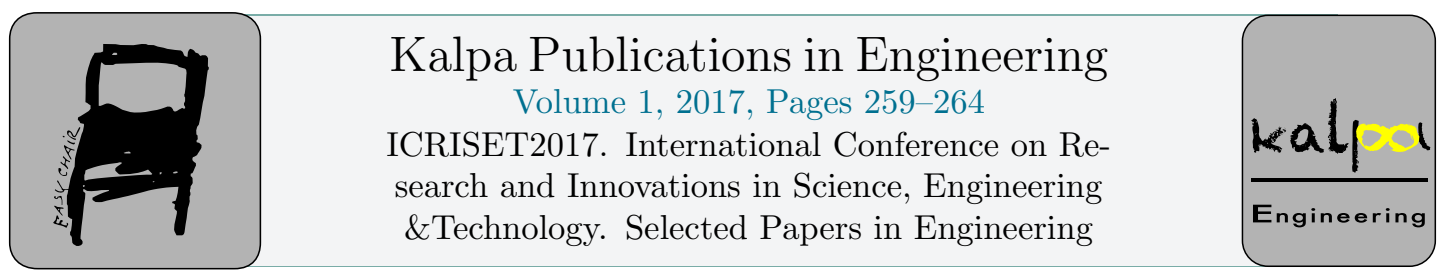

\title{
Analysis of Turn Table Assembly of Semi- Automatic High Pressure Molding Machine
}

\author{
Kaushal A. Patel ${ }^{1,4}$, Dr. Vina D. Chauhan ${ }^{2,4}$ and Dhara P. Trivedi ${ }^{3,4}$ \\ ${ }^{1}$ M.Tech, Machine Design \\ ${ }^{2}$ Professor, Mechanical Department \\ ${ }^{3}$ Assistant Professor, Mechanical Department \\ ${ }^{4}$ B. V. M. Engineering College, Vallabh Vidhyanagar, India \\ patel.kaushal012@gmail.com, vdchauhan@bvmengineering.ac.in, \\ dptrivedi@bvmengineering.ac.in
}

\begin{abstract}
Turn table assembly used in semi-automatic high pressure molding machine for rotating side arm that carries the bolster and stripper assembly by $180^{\circ}$ and stop the motion of the assembly at a desired position in specific time limit. The main function of turn table is to handle high torque because of heavy weight and inertia of the mold box and bolster stripper assembly. This paper explains design and analysis of the different components of turn table assembly.
\end{abstract}

\section{Introduction}

Now a days most common method used to make a metal casting is a green sand molding. During this process, sand is coated with a mixture of bentonite clay, water and other additives. These additives help to harden and maintain the mold shape to withstand pressure of the pouring molten metal. This mixture of green sand is compacted by hand or through mechanical force around a pattern to create a mold. This mechanical force can be applied by jolting, slinging, impact or squeezing. Most of the semi-automatic plant use squeezing process for compacting of sand because this process is most preferable for high volume work. High pressure, high density molding normally produces a well-compacted mold, which have a better surface finishes, casting dimensions and tolerances. Turn table use to rotate that bolster and stripper assembly with the mold box carried on its side arm. This $180^{\circ}$ rotation takes place by the hydraulic cylinder. When the cylinder is retracted turn table turns through $90^{\circ}$ rotation and when cylinder is extracted, turn table turn through another $90^{\circ}$ rotation. Speed of the rotation is decided on the basis of number of mold required. Thus, turn table assembly provides the $180^{\circ}$ indexing of bolster and stripper with box to allow alternate cope and drag during production cycle. The turn table is designed on the basis of the weight of bolster and stripper assembly, mold box and side arm of the machine. 


\section{Overview of the components of Turn Table}

\subsection{Components of Turn Table to be designed}

For designing turn table, components like Column for turn table, pivot shaft, bearing housing, turn table, Side arm, bottom and top bearing cover, Bushes for the pivot shaft and tie rod guide, cylindrical pin have to design first as it is the most critical component of assembly.

- Column for turn table: The commonly used shape of the Column is hollow cylinder so as to withstand four or five times more weight than square columns before catastrophic failure. This column will be joined with the help of plug weld on the circumference.

- Pivot Shaft: it is short length of the shaft, which support the rotating or turning part and another end terminates in the bearing.

- Bearing housing: it is used to provide support for a turning shaft with the help of compatible bearings and various accessories. It is mostly made up of a cast iron or cast steel

- Side arm: Side arm is a simply hollow channel on which four L-support is connected by the bolts each side and L-support carries whole weight of the bolster and stripper assembly on the shorter arm of L-support.

- Turn table: turn table is a simply extended flange which connects the side arm from the one end and another end is welded with the plate which is bolted with the pin connection.

- Cylindrical pin: Pin connection used to connect the cylindrical column with hydraulic cylinder like a knuckle joint. It is a most critical component of assembly, during the material selection special care should be taken. Material whose tensile strength is much higher that type of material is selected.

- Bushes: they are mostly used between two moving or rotating parts. It is made up of the material, which have higher wear resistance.

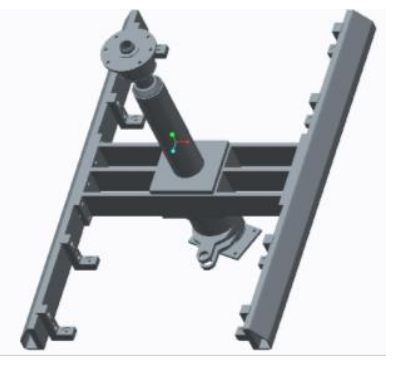

Figure 1: Turn table assembly

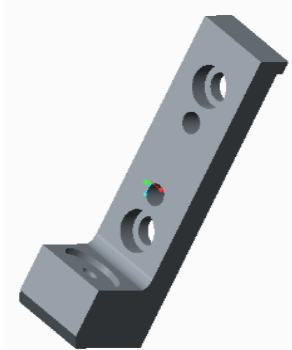

Figure 3: L-Support of Side arm

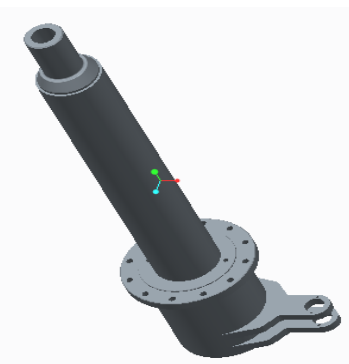

Figure 2: Column for Turn Table

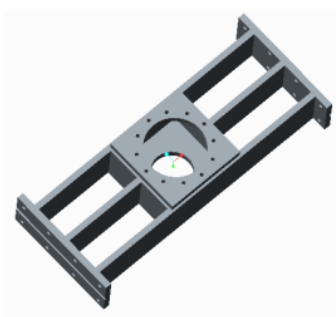

Figure 5: Turn Table

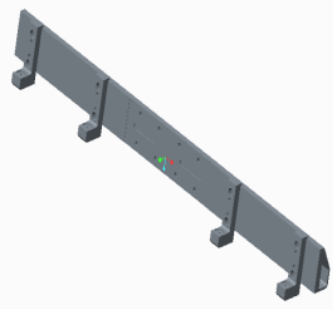

Figure 3: Side Arm of Turn table 


\subsection{Standard Components}

Hydraulic cylinder, tapered roller bearing, deep groove ball bearing, oil seal, hexagonal bolts and nuts, parallel keys are used to make whole assembly alive. This all components are outsourced.

- Hydraulic Cylinder: It is power pack which provide motion to whole turn table assembly. In such application cylinder with cushion is used to prevent sudden collision at the time of stopping.

- Tapered roller bearing: It is used at the bottom of the turn table column. Reason behind selecting tapered roller is to prevent a sudden lowering of whole assembly due to selfweight of the components.

- Deep groove ball bearing: it is used in the upper part of turn table column which only align the axis of the rotation with the axis of turn table column.

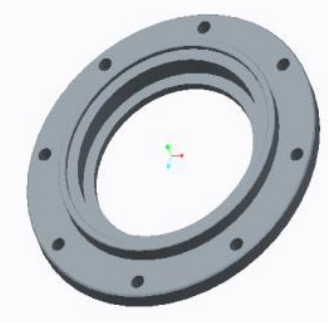

Figure 6: Bearing Housing
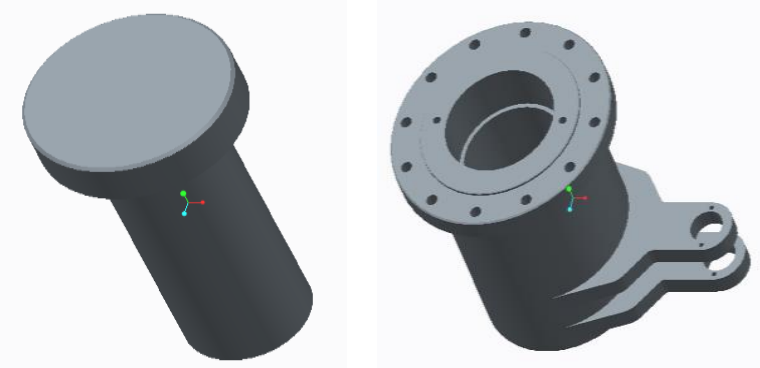

Figure 7: Pin Connection

\section{Design and Calculations}

- $\quad$ Force required by hydraulic cylinder: Turn table rotates whole bolster and stripper assembly with mould box from steady condition, and after completion of $180^{\circ}$ rotation gradually stops the motion. Turn table takes required time to complete the rotation. From these data from Table Free Body Diagram (FBD) is generated which is shown in figure 8.

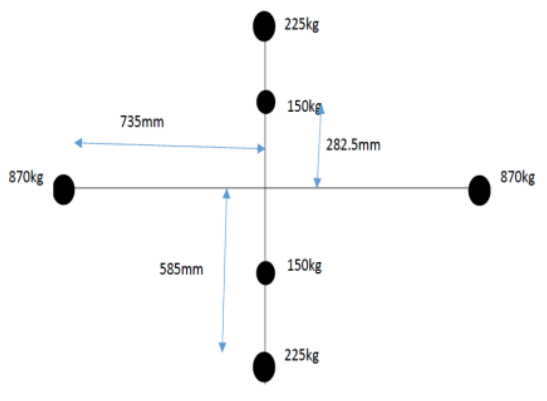

Table 1: Data for weight and distance of CG

\begin{tabular}{|c|c|c|}
\hline $\begin{array}{c}\text { Name of } \\
\text { component }\end{array}$ & $\begin{array}{c}\text { Weight } \\
\text { (kg) }\end{array}$ & $\begin{array}{c}\text { Distance of the CG from } \\
\text { the column centre (mm) }\end{array}$ \\
\hline Turn Table & 300 & 282.5 \\
\hline Side arm & 450 & 585 \\
\hline $\begin{array}{c}\text { Bolster and } \\
\text { Stripper assembly }\end{array}$ & 1740 & 735 \\
\hline
\end{tabular}

Figure 8: FBD for different components

- Mass moment of inertia of the mould box, bolster and stripper assembly and side arm: 


$$
\begin{aligned}
& \mathrm{I}=\mathrm{M}_{1} \mathrm{R}_{1}^{2}+\mathrm{M}_{2} \mathrm{R}_{2}^{2}+\ldots .+\mathrm{M}_{\mathrm{n}} \mathrm{R}_{\mathrm{n}}^{2} \\
& \mathrm{I}=1117.934625 \mathrm{~kg} \cdot \mathrm{m}^{2}
\end{aligned}
$$

- Angular acceleration in turn table:

Here assume that turn table start rotating from steady state condition and at the quarter of the rotation attains maximum speed and after that start retarding the angular velocity of the whole assembly. So from the equation of average angular velocity,

$$
\begin{aligned}
& \Theta=0.5 \times \alpha \times \mathrm{t}^{2} \\
& \alpha=0.2564 \mathrm{rad} / \mathrm{sec}^{2}
\end{aligned}
$$

Same for another quarter half of the rotation deceleration take place so,

$$
\alpha=-0.2564 \mathrm{rad} / \mathrm{sec}^{2}
$$

- Torque which have to overcome by the hydraulic cylinder:

$$
\mathrm{T}=286.6384379 \mathrm{~N} \cdot \mathrm{m}
$$

- Maximum force required by the hydraulic cylinder:

The torque is overcome by the hydraulic cylinder which is connected by the cylindrical pin of the turn table column. Distance of the cylindrical pin is $255 \mathrm{~mm}$ from the center of the turn table.

Maximum force exerted by the cylinder on the pin to overcome the torque.

$$
\mathrm{F}_{\max }=64407.86887 \mathrm{~N}
$$

\subsection{Design of Pin connection}

$$
\begin{aligned}
& P=\text { Maximum Tensile Load }=64407.86887 \mathrm{~N} \\
& D=\text { Outer diameter of the fork end } \\
& d=\text { Inner diameter of the eye } \\
& t_{1}=\text { Thickness of the fork (double eye) end } \\
& t_{2}=\text { Thickness of the single eye end }
\end{aligned}
$$

- The Dimensions obtained by detailed design are as follows.

Diameter of the $\operatorname{rod}=\mathrm{d}=24 \mathrm{~mm}$.

Diameter of the pin $=\mathrm{d}=24 \mathrm{~mm}$.

Outer diameter of the eye $\mathrm{D}=48 \mathrm{~mm}$.

Thickness of the fork (double eye) end $=\mathrm{t}_{1}=18 \mathrm{~mm}$.

Thickness of the single eye end $=\mathrm{t}_{2}=30 \mathrm{~mm}$.

Pin is checked for shear stress, Where shear stress $\tau=71.186 \mathrm{~N} / \mathrm{mm}^{2}<100 \mathrm{~N} / \mathrm{mm}^{2}$

Double eye checked under a tension, where tensile stress $\sigma_{\mathrm{t}}=74.564 \mathrm{~N} / \mathrm{mm}^{2}<140 \mathrm{~N} / \mathrm{mm}^{2}$

Single eye checked under a tension, Where tensile stress $\sigma_{\mathrm{t}}=89.455 \mathrm{~N} / \mathrm{mm}^{2}<150 \mathrm{~N} / \mathrm{mm}^{2}$ 
Double eye is checked for shear stress, Where shear stress $\tau=74.564 \mathrm{~N} / \mathrm{mm}^{2}<95 \mathrm{~N} / \mathrm{mm}^{2}$ The Design is checked for failure and found safe from the following data.

\section{Analysis of components of Turn Table Assembly}

\subsection{Stresses and deformation in fork end}

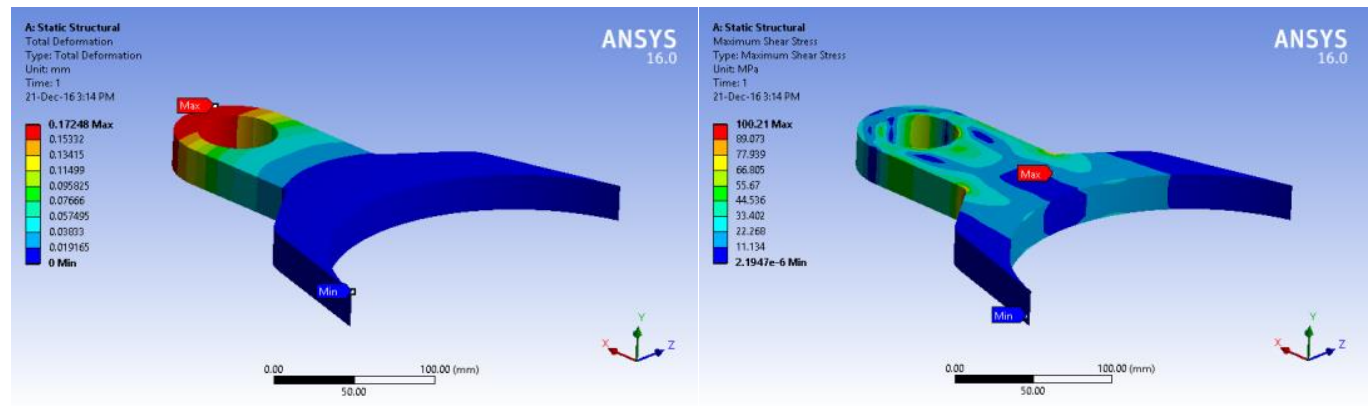

Figure 9: Total deformation and maximum shear stress in fork end

\subsection{Stresses and deformation in pin}

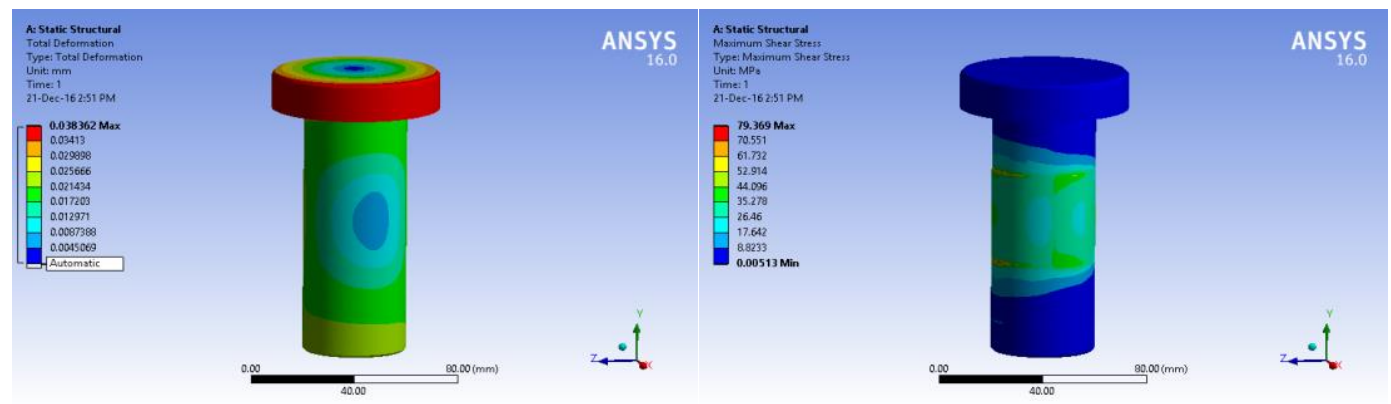

Figure 10: Total deformation and maximum shear stress in the Pin

\subsection{Stresses and deformation in L-support of side arm}

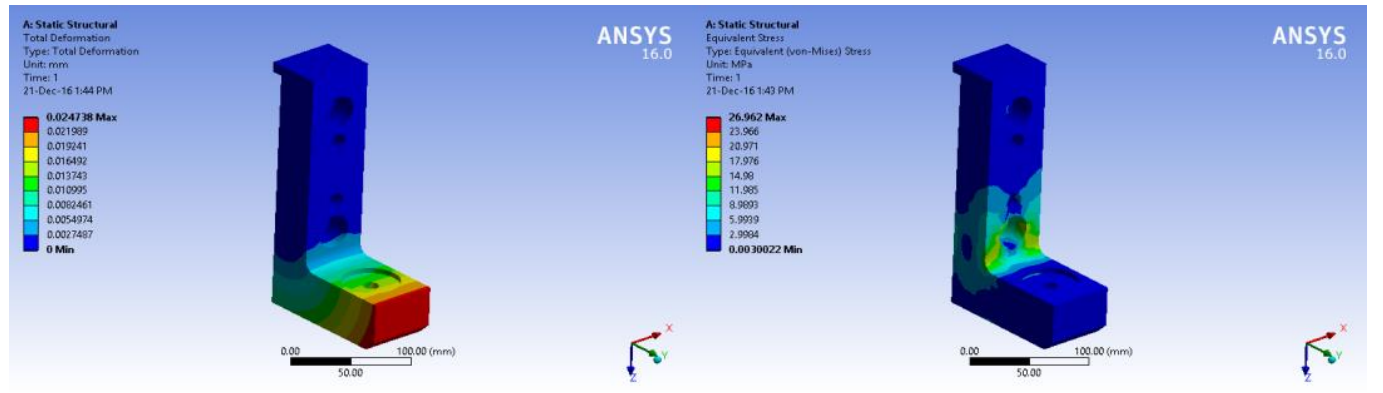

Figure 11: Total deformation and equivalent stresses in L-Support 


\section{- Results from the analysis:}

Table 2: Deformation and stresses in components

\begin{tabular}{|c|c|c|c|}
\hline Name of component & Max. deformation (mm) & Min. stress (MPa) & Max. stress (MPa) \\
\hline $\begin{array}{c}\text { Fork end of the pin } \\
\text { connection }\end{array}$ & 0.17248 & 0.000002194 & 100.21 \\
\hline $\begin{array}{c}\text { L-support of the side } \\
\text { arm }\end{array}$ & 0.024738 & 0.0030022 & 26.962 \\
\hline Pin & 0.038362 & 0.00513 & 79.369 \\
\hline
\end{tabular}

Results shows that all stresses generated in all the components is less than allowable stress of the material and deformation in the all components are negligible.

\section{Conclusion}

It is concluded that, the dimensions obtained from the design, are analysed by ANSYS and obtains results are within specified limit of the allowable stresses of the material. Analysis results also show that total deformation is negligible in all the components.

\section{References}

[1] William Orthowein, Machine Component Design, JAICO Publishing house

[2] V.B. Bhandari, Introduction to Machine Design, Tata McGraw Hill Education Pvt. Ltd.-2001

[3] Pandya and Shah, Machine Design Charotar Publication House, thirteenth edition

[4] B.S. Raghuwanshi, Workshop Technology Vol. 1, Dhanpatrai \& Co.Tenth Edition

[5] Richard G. Budynas and J. Keith Nisbett, Shigley's Mechanical Engineering Design, Tata McGraw Hill Education Pvt. Ltd. Ninth Edition

[6] S K Duggal, Design of steel Structures, Tata McGraw Hill Education Pvt. Ltd., Third edition-2009

[7] A Text book of Machine Design by R.S. Khurmi and J.K. Gupta, S. Chand Publication 